\title{
Short-term cardiovascular impact and change in the natural history of the disease after high-quality dialysis therapy
}

\author{
Impacto cardiovascular a corto plazo y cambio de la historia natural de la enfermedad \\ tras terapia dialítica de alta calidad
}

\author{
Mónica Sánchez-Cárdenas ${ }^{*}$, Jorge E. Aceituno-Melgar², and Héctor Pérez-Grovas ${ }^{1}$ \\ ${ }^{1}$ Department of Nephrology; ${ }^{2}$ Department of Cardiology, Instituto Nacional de Cardiología Ignacio Chávez, Mexico City, Mexico
}

This is the case of a previously healthy 28 -year-old man.

Current complaint started with the presence of nausea, vomiting, and poor general condition. During assessment, blood urea nitrogen (BUN) at $142 \mathrm{mg} / \mathrm{dL}$ and creatinine at $12.8 \mathrm{mg} / \mathrm{dL}$ were documented. Due to limited financial resources, immediately starting dialysis therapy was not possible and only medical management was initiated. After symptomatic progression, dialysis therapy was started 10 months later, with only two sessions being received per week.

He was evaluated by our institution 3 months after the start of renal replacement therapy. He attended due to the presence of a hypertensive emergency with noticeable and progressive visual acuity decrease during the previous week. Grade III severe hypertensive retinopathy was diagnosed, with predominantly right bilateral macular edema. In addition, dyspnea on high-intensity exertion, generalized itching, and sleep-wake cycle inversion were documented; he had uncontrolled hypertension, bibasal crackles, lower limb edema, and data consistent with wasting $(56 \mathrm{~kg}$ of weight, body mass index at 19.4). Post-dialysis laboratories showed BUN $112 \mathrm{mg} / \mathrm{dL}$, phosphorus $8.4 \mathrm{mg} / \mathrm{dL}$, uric acid $8.9 \mathrm{mg} / \mathrm{dL}$, and potassium $5.9 \mathrm{mg} / \mathrm{dL}$. He was admitted to the hospital.

At admission, he had uncontrolled hypertension that was refractory to the use of triple antihypertensive regimen at the highest dose. We documented flame-shaped hemorrhages between the arcades, macular star, and hard exudates throughout the papillomacular bundle in both eyes (severe hypertensive choroidopathy), with severe impact on visual acuity and need for help with instrumented activities.

Baseline transthoracic echocardiogram showed dilatation of the four chambers, eccentric hypertrophy of the left ventricle, preserved biventricular systolic function, without mobility alterations, and left ventricular diastolic dysfunction; significant tricuspid regurgitation, moderate mitral regurgitation, and mild aortic/pulmonary regurgitation; pulmonary artery systolic pressure was estimated at $67 \mathrm{mmHg}$ (Fig. 1).

The right cardiac catheterization was performed with a normotensive right atrium (1 $\mathrm{mmHg}$ ), right ventricular systolic pressure of $26 \mathrm{mmHg}$, and pulmonary arterial pressure of $24 / 14 / 3 \mathrm{mmHg}$ being recorded.

Hypervolemia was corrected by ultrafiltration, which enabled gradual tapering of antihypertensive drugs and nutritional parameters' improvement. He was discharged 3 weeks later, with body dry weight of $49.5 \mathrm{~kg}$ by bioelectrical impedance, using only $50 \mathrm{mg}$ of losartan per day. Laboratories showed uric acid $3.32 \mathrm{mg} / \mathrm{dL}$, BUN $21.3 \mathrm{mg} / \mathrm{dL}$, phosphorus $5.5 \mathrm{mg} / \mathrm{dL}$, albumin $4.45 \mathrm{~g} / \mathrm{dL}$, LDL $102.9 \mathrm{mg} / \mathrm{dL}$, and HDL $42.5 \mathrm{mg} / \mathrm{dL}$.

After discharge, management was continued in our center, granting $10 \mathrm{~h}$ of hemodiafiltration per week, with an

\section{Correspondence:}

*Mónica Sánchez-Cárdenas

E-mail: dra_monicasanchez@ hotmail.com

2604-7063 / @ 2020 Instituto Nacional de Cardiología Ignacio Chávez. Published by Permanyer. This is an open access article under the CC BY-NC-ND license (http://creativecommons.org/licenses/by-nc-nd/4.0/).

Available online: 25-05-2021

Arch Cardiol Mex (Eng). 2021;91(1):128-131 www.archivoscardiologia.com

Date of reception: 23-08-2019

Date of acceptance: 12-05-2020 


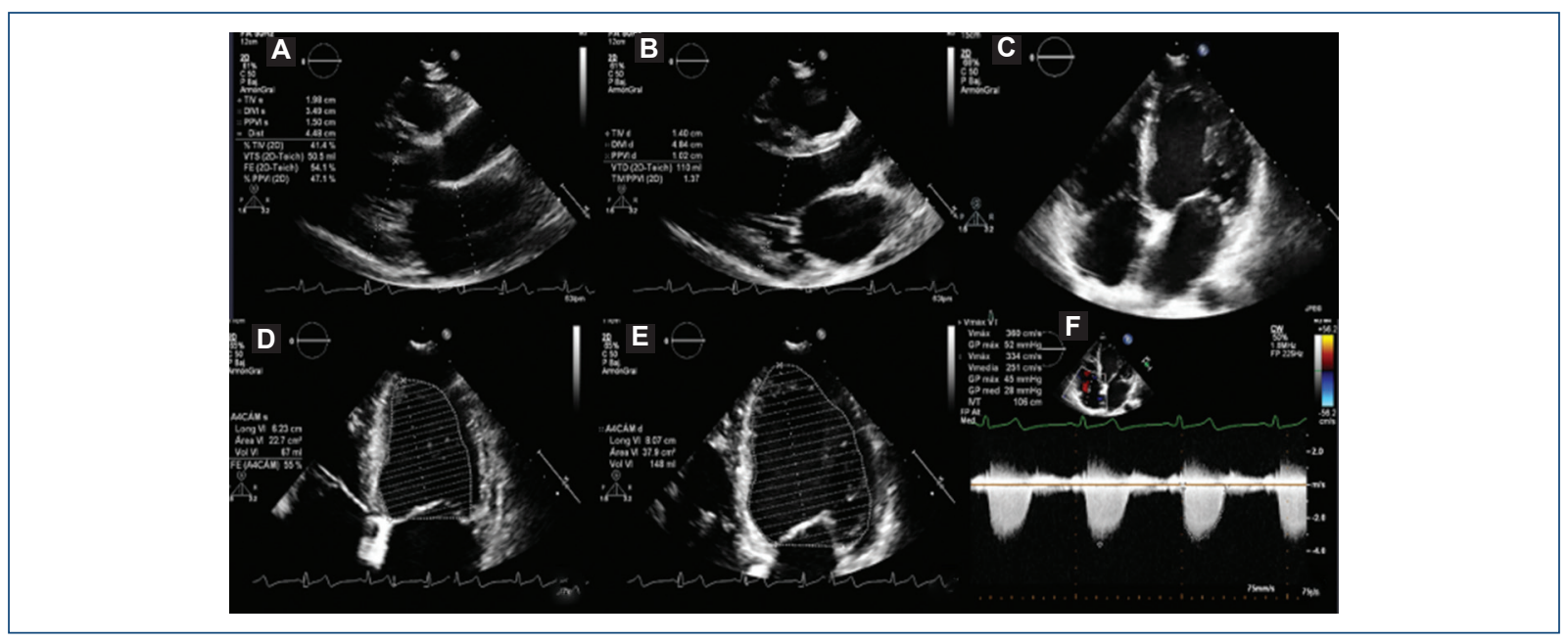

Figure 1. Baseline transthoracic echocardiogram. A and B: long parasternal axis; left ventricular internal diameter at diastole (B) and systole (A). C, D, and E: four-chamber apical view (C); end-diastolic (E) and end-systolic (D) volumes are shown, with LVEF of $57 \%$. F: 4-chamber apical view with continuous Doppler, showing tricuspid regurgitation maximum speed at $360 \mathrm{~cm} / \mathrm{s}$.

LVEF: left ventricular ejection fraction.

average of $23 \mathrm{~L}$ replacement and $22 \mathrm{~km}$ of cycling at each dialysis session. One week later, antihypertensive drugs complete withdrawal was possible, with blood pressure within goals. The transplantation protocol was completed, with his 48-year-old healthy mother acting as donor.

After 6 weeks on regular and optimized dialysis therapy, a new echocardiogram showed concentric remodeling of the left ventricle, normal biventricular systolic function, normal pulmonary artery systolic pressure, and mild mitral and tricuspid regurgitation (Table 1 and Fig. 2).

Two months later, kidney transplantation was carried out. He had no surgical or infectious peri-transplantation complications and was discharged home 1 week later. During follow-up, 6 months after transplantation, small fine hard exudates were recorded in the papulomacular bundle, without macular star and without bleeding, with marked improvement in visual acuity (Fig. 3).

At present, at 1 year post-transplantation, he is only on maintenance immunosuppressive therapy with a triple regimen (prednisone, tacrolimus, and mycophenolate), with baseline creatinine of $0.9 \mathrm{mg} / \mathrm{dL}$, normotensive, and weighing $65 \mathrm{~kg}$. He has returned $100 \%$ to his work activities.

\section{Discussion}

We present the case of a man at his third decade of life, with chronic kidney disease of undetermined
Table 1. Baseline and control echocardiographic characteristics

\begin{tabular}{|c|c|c|}
\hline & $\begin{array}{c}\text { Baseline } \\
\text { echocardiogram }\end{array}$ & $\begin{array}{c}\text { Control } \\
\text { echocardiogram } \\
\text { (6 weeks) }\end{array}$ \\
\hline $\begin{array}{l}\text { Left ventricle } \\
\text { LVEF } \\
\text { E/A ratio } \\
\text { E/é ratio } \\
\text { End-diastolic volume }\end{array}$ & $\begin{array}{c}57 \% \\
1.65 \\
8.99 \\
100 \mathrm{ml} / \mathrm{m}^{2}\end{array}$ & $\begin{array}{c}57 \% \\
1.12 \\
4.5 \\
72 \mathrm{ml} / \mathrm{m}^{2}\end{array}$ \\
\hline $\begin{array}{l}\text { Right ventricle } \\
\text { TAPSE } \\
\text { RVOT-FS } \\
\text { PASP (mmHg) } \\
\text { Basal diameter } \\
\text { Middle third diameter } \\
\text { Longitudinal diameter } \\
\text { Tricuspid annulus } \\
\text { S-wave }\end{array}$ & $\begin{array}{c}27 \mathrm{~mm} \\
41 \% \\
67 \\
46 \mathrm{~mm} \\
37 \mathrm{~mm} \\
95 \mathrm{~mm} \\
14 \mathrm{~cm} / \mathrm{s}\end{array}$ & $\begin{array}{c}21 \mathrm{~mm} \\
38 \% \\
33 \\
40 \mathrm{~mm} \\
31 \mathrm{~mm} \\
78 \mathrm{~mm} \\
11 \mathrm{~cm} / \mathrm{s}\end{array}$ \\
\hline $\begin{array}{l}\text { Left atrium } \\
\text { Indexed volume }\end{array}$ & $57 \mathrm{ml} / \mathrm{m}^{2}$ & $30 \mathrm{ml} / \mathrm{m}^{2}$ \\
\hline $\begin{array}{l}\text { Right atrium } \\
\text { Indexed volume } \\
\text { Estimated pressure }\end{array}$ & $\begin{array}{l}60 \mathrm{ml} / \mathrm{m}^{2} \\
15 \mathrm{mmHg}\end{array}$ & $\begin{array}{l}31 \mathrm{ml} / \mathrm{m}^{2} \\
5 \mathrm{mmHg}\end{array}$ \\
\hline Vena cava & $\begin{array}{l}>21 \mathrm{~mm} \text { with } \\
<50 \% \text { collapse }\end{array}$ & $\begin{array}{c}\text { Normal } \\
>50 \% \text { collapse }\end{array}$ \\
\hline
\end{tabular}

LVEF: left ventricular ejection fraction; TAPSE: tricuspid annular plane systolic excursion; RVOT-FS: right ventricular outflow tract fractional shortening; PASP: pulmonary artery systolic pressure.

etiology, on chronic dialysis therapy, with multiple data indicative of suboptimal dialysis (including severe volume expansion). This represents a classic case of 

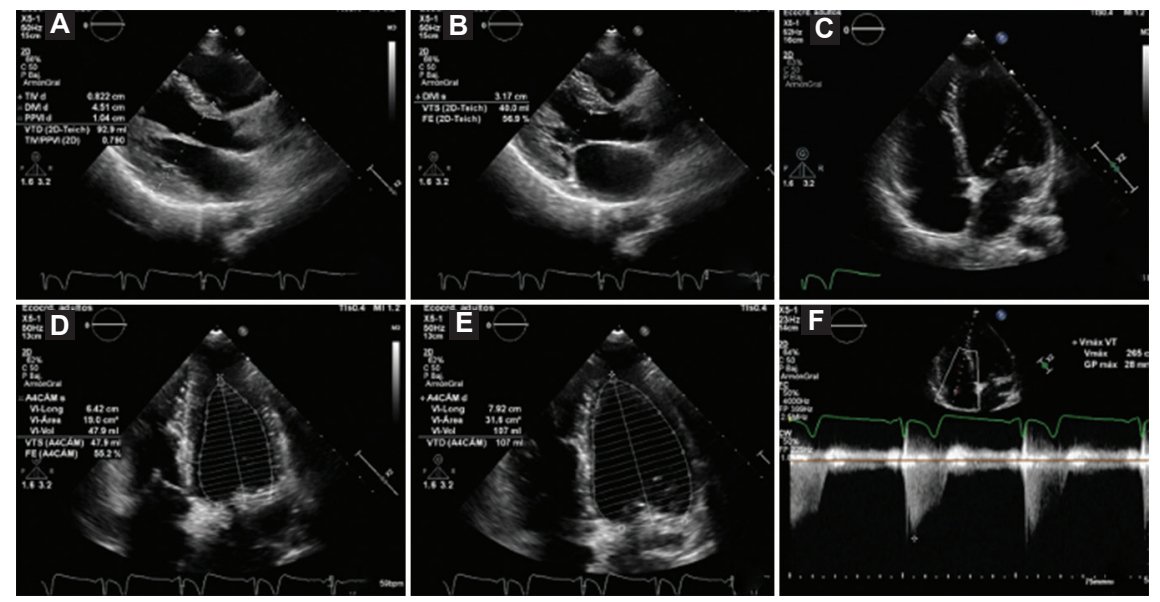

Figure 2. Control transthoracic echocardiogram. A and B: long parasternal axis; left ventricular internal diameter at diastole (A) and systole (B). C-E: 4-chamber apical view (C); end-diastolic (E) and end-systolic (D) volumes are observed, with an LVEF of $57 \%$. F: four-chamber apical view with continuous Doppler, showing tricuspid regurgitation maximum speed.

LVEF: left ventricular ejection fraction.

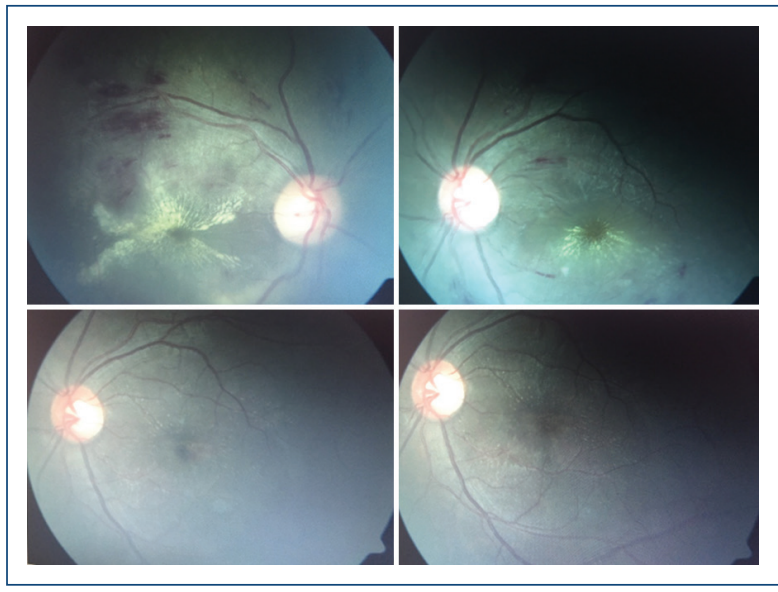

Figure 3. Fundus before optimizing dialysis management (upper images) and 6 months after transplantation (lower images). Initially, the presence of extensive hemorrhages and a macular star predominantly in the right eye is observed. Six months after transplantation, the macular star has disappeared, with no significant hemorrhages being observed.

hypertension in the context of chronic volume overload with target organ damage clearly identified at the ophthalmological level. After quality dialysis therapy was implemented, we were able to record a favorable short-term cardiac impact (in the context of classically reported echocardiographic data in states of volume overload), as well as ophthalmological positive repercussions.

Today, we know that one out of every three patients with chronic kidney disease will have a major cardiovascular event recorded in their history ${ }^{1}$. In addition to the inflammatory state that usually accompanies kidney function chronic loss, persistent volume expansion and elevation of so-called uremic toxins will have a direct cardiovascular impact ${ }^{2}$.

The state of overload, anemia and chronic hypertension, will lead to the presence of the left ventricular hypertrophy (with a direct prognostic impact on cardiovascular and all-cause mortality). On the other hand, the latent role of the presence of uremic heart disease should be considered. So far, there are more than 90 identified uremic toxins; those of small size (molecular weight under 500 Daltons) are easily dialyzable and are used as markers of dialysis quality ${ }^{3}$. However, larger or protein-bound molecules represent a challenge, given the difficulty in properly removing them with current dialysis techniques. Creatinine has been shown to decrease cardiac contractility in vitro, and urea increases oxygen consumption by cardiac cells $s^{4,5}$. On the other hand, hyperphosphatemia, a classic finding in chronic kidney patients, favors vascular and tissue calcification.

Among medium-sized molecules, $\beta 2$-microglobulin represents the classic example. For its adequate elimination, the convective power of hemodiafiltration is 
required, which is provided at some tertiary care centers, but is of limited access in most communities. In addition to the direct link shown in atherogenesis, medium-sized molecules and those bound to proteins play a very important role in the development of cardiac fibrosis.

Based on the aforementioned pathophysiological mechanisms, successful kidney transplantation is associated with reversal of the pathological remodeling changes at the cardiac level that is classic of chronic disease and long-standing dialysis therapy. It is associated with a clear improvement of systolic function in the short term and regression of hypertension-induced hypertrophic heart disease ${ }^{6}$.

Considering that cardiovascular mortality in patients on dialysis is 10-30 times higher than that of the general population, having access to quality dialysis therapy in a timely manner completely changes the history of the disease, even before transplantation, as in the case herein reported.

\section{Acknowledgments}

The authors thank the collaboration of Dr Gabriela del Carmen Calvo Leroux from the, Echocardiography Department at the National Institute of Cardiology.

\section{Funding}

None.

\section{Conflicts of interest}

The authors declare that they have no conflicts of interest.

\section{Ethical disclosures}

Protection of human and animal subjects. The authors declare that no experiments were performed on humans or animals for this research.

Confidentiality of data. The authors declare that they have followed the protocols of their work center on the publication of patient data.

Right to privacy and informed consent. The authors declare that no patient data appear in this article.

\section{References}

1. Srivastava A, Kaze AD, McMullan CJ, Isakova T, Waikar SS. Uric acid and the risks of kidney failure and death in individuals with CKD. Am J Kidney Dis. 2018;71(3):362-70.

2. Sarnak MJ, Levey AS, Schoolwerth AC, Coresh J, Culleton B, Hamm LL, et al. Kidney disease as a risk factor for development of cardiovascular disease: a statement from the American Heart Association Councils on Kidney in Cardiovascular Disease, High Blood Pressure Research, Clinical Cardiology, and Epidemiology and Prevention. Circulation. 2003;108(17):2154-69.

3. Lekawanvijit S. Cardiotoxicity of uremic toxins: A driver of cardiorenal syndrome. Toxins. 2018;10(9):352.

4. Vanholder R, Gryp T, Glorieux G. Urea and chronic kidney disease: the comeback of the century? (in uraemia research). Nephrol Dial Transplant. 2018;33(1):4-12.

5. Weisensee D, Low-Friedrich I, Riehle M, Bereiter-Hahn J Schoeppe W. In vitro approach to 'uremic cardiomyopathy'. Nephron. 1993;65(3):392-400.

6. Zapolski T, Furmaga J, Wysokinski AP, Wysocka A, Rudzki S, Jaroszynski $A$. The atrial uremic cardiomyopathy regression in patients after kidney transplantation - the prospective echocardiographic study. BMC nephrology. 2019;20(1):152. 